\title{
Prevotella intermedia/nigrescens Group
}

National Cancer Institute

\section{Source}

National Cancer Institute. Prevotella intermedia/nigrescens Group. NCI Thesaurus. Code C86671.

A non taxonomic grouping of bacteria assigned to the Prevotella genus that include the

P. intermedia and P. nigrescens species. 